\title{
Liver Injury with Ulipristal Acetate: Exploring the Underlying Pharmacological Basis
}

\author{
Milo Gatti ${ }^{1}$ (i) Elisabetta Poluzzi $i^{1}$ (i) Fabrizio De Ponti ${ }^{1}$ (D) Emanuel Raschi ${ }^{1}$ (i)
}

Published online: 3 August 2020

(c) The Author(s) 2020

\begin{abstract}
Introduction The European Medicines Agency has suspended the use of ulipristal acetate (UPA) in the treatment of uterine fibroids and is reassessing its association with a risk of liver injury.

Objectives Our objectives were to characterize the post-marketing reporting of drug-induced liver injury (DILI) with UPA and investigate the underlying pharmacological basis.

Methods We queried the worldwide FDA Adverse Event Reporting System and performed a disproportionality analysis, selecting only hepatic designated medical events (DMEs) where UPA was reported as suspect. The reporting odds ratios (RORs) were calculated, and we considered a lower limit of the 95\% confidence interval (LL95\% CI) $>1$ as significant. Physiochemical/pharmacokinetic features were extracted to assess the risk of hepatotoxicity by applying predictive DILI risk models. Mifepristone and leuprolide were selected as comparators.

Results A significantly higher proportion of liver disorders was reported for UPA than for mifepristone (2.9 vs. $0.8 \%$; $p<0.00001)$ and leuprolide (2.9 vs. $1.6 \% ; p=0.015)$. As regards hepatic DMEs, statistically significant RORs were found for autoimmune hepatitis ( $N=5$; LL95\% CI 16.8), DILI ( $n=5$; LL95\% CI 5.9), and acute hepatic failure ( $N=5$; LL95\% CI 9.3). No signals of DILI emerged for mifepristone and leuprolide acetate. UPA and mifepristone showed high lipophilicity and hepatic metabolism (predicted intermediate DILI risk). Leuprolide exhibited contrasting features, resulting in no DILI concern. Inhibition of different liver transporters and the presence of a reactive metabolite were also recognised for UPA. Conclusion Different drug properties previously linked to the occurrence of DILI may partially explain the reporting pattern observed with UPA. Our "bedside-to-bench" approach may support regulators in the risk-benefit assessment of UPA.
\end{abstract}

\section{Introduction}

Ulipristal acetate (UPA) is an orally active selective progesterone-receptor modulator. In 2012, the European Medicines Agency (EMA) approved UPA $5 \mathrm{mg} /$ day for the treatment of moderate to severe symptoms of uterine fibroids in adult women of reproductive age, with the treatment duration limited to 3 months [1]. It is also approved for emergency contraception as one single $30 \mathrm{mg}$ dose.

Electronic supplementary material The online version of this article (https://doi.org/10.1007/s40264-020-00975-8) contains supplementary material, which is available to authorized users.

Fabrizio De Ponti

fabrizio.deponti@unibo.it

1 Pharmacology Unit, Department of Medical and Surgical Sciences, Alma Mater Studiorum, University of Bologna, Via Irnerio 48, 40126 Bologna, Italy
In February 2018, the EMA issued temporary restrictive measures for UPA after five cases of drug-induced liver injury (DILI) were reported, four of which required liver transplantation. The Pharmacovigilance Risk Assessment Committee (PRAC) subsequently made temporary recommendations advising physicians not to take on new patients or initiate new treatment courses. In May 2018, the status of UPA as a potential DILI-inducing agent was neither confirmed nor fully ruled out; however, in eight cases of serious liver injury the role of UPA was deemed possible, and the PRAC made recommendations to minimize the risk of liver injury by forbidding its use in women with underlying hepatic disorders or liver enzyme levels more than twice the upper limit of normal [2-4].

Subsequent analyses reported that elevation in liver enzyme levels was recognised in 11 of 1868 women $(0.6 \%)$ treated with UPA in pivotal trials, of which only one received the approved dosage of $5 \mathrm{mg} /$ day, and none met Hy's Law $[5,6]$. Furthermore, a retrospective study assessing liver 


\section{Key points}

This original research explored the possible underlying pharmacological basis involved in liver injury associated with ulipristal acetate by applying a "bedside-to-bench" mixed approach that included estimating the extent of life-threatening hepatic reactions in the real world and assessing physiochemical and pharmacokinetic parameters correlated with drug-induced liver injury.

The over-reporting of severe life-threatening hepatic reactions, particularly autoimmune hepatitis, associated with ulipristal acetate in post-marketing surveillance may be partially explained by its physiochemical (high lipophilicity) and pharmacokinetic (hepatic metabolism, long half-life, inhibition of liver transporters, reactive metabolite formation) features.

This mixed approach may be helpful for regulators in supporting risk-benefit evaluation during the current suspension issued by the European Medicines Agency for ulipristal acetate in the management of uterine fibroids.

function in 162 women treated with UPA found no case of liver injury or elevation in enzyme levels [7].

New cases of serious hepatic injury-one requiring liver transplantation [8] — despite adherence to the 2018 PRAC recommendations, led the EMA to reassess liver injury risk and, on 12 March 2020, issue a suspension of UPA for the treatment of uterine fibroids.

\section{Objective}

In this "regulatory limbo", pharmacology may aid investigations into the potential underlying mechanisms of DILI associated with UPA and with estimating the extent of reporting in post-marketing surveillance.

Therefore, to explore the relationship between the use of UPA and the occurrence of DILI, we implemented a "twostep" approach based on (1) analysis of spontaneous reports submitted to the US FDA Adverse Event Reporting System (FAERS) database, including disproportionality analysis for hepatic reactions classified as designated medical events (DMEs), namely rare serious adverse events (AEs) with a recognized drug-attributable risk [9]; and (2) review of physiochemical and pharmacokinetic features known to be potentially involved in DILI.

\section{Methods}

\subsection{Pharmacovigilance Evaluation}

We performed an observational retrospective disproportionality analysis to highlight and characterize hepatic AEs of clinical interest with (higher than expected) increased reporting. The FAERS database (public dashboard), the US repository of AEs and medication errors comprising more than 18 million reports gathered worldwide, was queried to retrieve UPA reports recorded between the first quarter of 2011 and the fourth quarter of 2019 (search performed on 8 April 2020). To assign a clinical priority to emerging hepatic safety issues, we used the public list of DMEs developed by the EMA [9]. Specifically, seven of the 62 different reactions included in the public list of DMEs concern hepatic AEs (acute hepatic failure, autoimmune hepatitis, DILI, hepatic failure, hepatic infarction, hepatic necrosis, and hepatitis fulminant). The reporting odds ratio (ROR) with relevant $95 \%$ confidence interval (CI) was calculated as a measure of disproportionality, using all other drugs/events recorded in FAERS as a comparator. Traditional criteria for signal detections were used, i.e., lower limit of the $95 \%$ CI of the ROR $>1$ with at least three cases of interest reported [10]. Cases were manually checked for duplicates using case identification and overlapping information among records, and, for ROR calculation, a case counts as many-fold as the number of hepatic events reported. Case-by-case assessment for concomitant drugs with hepatotoxic potential was also performed based on classification proposed by Björnsson et al. [11], focusing on agents in category A and B.

For comparison, we also extracted data on mifepristone, a well-known progesterone-receptor antagonist available for pregnancy termination [12], and leuprolide acetate, a synthetic agonist analogue of gonadotropin-releasing hormone first approved for the treatment of advanced prostatic cancer and also currently used for the management of uterine fibroids [13]. Mifepristone and leuprolide acetate were, respectively, selected according to affinity of chemical structure and comparable therapeutic indication (i.e., uterine fibroids).

\subsection{Pharmacological Assessment}

To investigate the potential underlying mechanisms of DILI associated with UPA, we performed a review of the physiochemical and pharmacokinetic features known to be potentially involved in DILI. In particular, properties such as threshold dose, lipophilicity, formation of reactive metabolites, oxidative stress, mitochondrial liability, hepatic 
metabolism, and inhibition of hepatic transporters can confer a risk for DILI, which may increase susceptibility to hepatotoxicity because of host-related factors such as female sex and age $[14,15]$.

We also queried public online prediction tools (namely, ADVERPred [16] and Vienna LiverTox Workspace [17]) to investigate the existence of physiochemical features associated with DILI and the interaction profile with liver transporters potentially involved in hepatic damage. Additionally, we applied the DILI risk model proposed by Chen et al. [18] based on lipophilicity, formation of reactive metabolites, and scheduled dose/peak concentration $\left(C_{\max }\right)$. According to the model, a score $>7$ indicates the most DILI concern/solid evidence, a score of 3-7 indicates less DILI concern/weak evidence, and a score $<3$ indicates no DILI concern/no evidence of hepatotoxicity. This so-called "rule-of-two" (Ro2) model, validated using $354 \mathrm{drugs}$, is a simple way to predict the severity of DILI in humans and has also been successfully applied to stratify DILI liability among direct-acting antivirals for hepatitis $C$ and cyclin-dependent kinase $4 / 6$ inhibitors to treat hormone receptor-positive breast cancer $[14,19]$.

Finally, we also reviewed the physiochemical and pharmacokinetic features of mifepristone and leuprolide acetate as a comparison.

\section{Results}

Data collected from FAERS for UPA, mifepristone, and leuprolide acetate are shown in Table 1. Overall, 578, 6220 , and 44,079 reports mentioning UPA, mifepristone, and leuprolide acetate, respectively, as the suspect agent were found. Serious cases ranged from $51.1 \%$ for mifepristone to $92.0 \%$ for UPA. A significantly higher proportion of liver disorders was reported for UPA than for mifepristone $(2.9$ vs. $0.8 \% ; p<0.00001)$ and leuprolide acetate $(2.9$ vs. $1.6 \% ; p=0.015)$ in the real world, although notoriety bias (i.e., increased reporting of hepatic injures following increased awareness of submitters) cannot be ruled out, given that eight of 17 reports were recorded after warnings issued by the EMA. As regards hepatic DMEs reported with UPA, statistically significant RORs were found for autoimmune hepatitis $(N=5$; ROR 40.6 ; $95 \%$ CI 16.8-97.9), DILI ( $N=5$; ROR 14.2; 95\% CI 5.9-34.3), and acute hepatic failure ( $N=5$; ROR 22.5 ; 95\% CI 9.3-54.2).

Conversely, no significant ROR was found for hepatic DMEs reported with mifepristone (eight cases of hepatic failure and three of DILI) and leuprolide acetate (Supplementary Materials 1). Overall, 60 hepatic DMEs were reported with leuprolide acetate, with hepatic failure $(N=32)$ the most represented. However, these events occurred in patients affected by advanced prostatic or breast cancer, and no life-threatening hepatic events were reported in the 17 women treated for uterine fibroids. Notably, concomitant hepatotoxic agents were retrieved in only $17.6 \%$ of UPA reports (all in category A) and in none of the autoimmune hepatitis cases.

The physiochemical and pharmacokinetic parameters retrieved for UPA [20, 21], mifepristone [22, 23], and leuprolide acetate $[13,24]$ are summarized in Table 2. Both UPA and mifepristone exhibited high lipophilicity (respectively, $\log$ P 4.45 and 5.43), hepatic metabolism, and inhibition of different liver transporters. A reactive metabolite was found for UPA, and Ro2 was positive for mifepristone. Prediction tools showed no risk of hepatotoxicity for these agents, except for cholestasis potentially due to mifepristone. Implementation of dose- and $C_{\max }$-based DILI scores resulted in less DILI concern/weak evidence of hepatotoxicity for both UPA (respectively, 4.82 and 5.75 patients) and mifepristone (respectively, 4.43 and 4.40 patients).

Conversely, leuprolide acetate showed contrasting properties, namely poor lipophilicity (LogP 1.04), lack of hepatic metabolism, and no impact on liver transporters. Prediction tools reported no risk of hepatotoxicity, and dose- and $C_{\max }$-based DILI scores resulted in no DILI concern/no evidence of hepatotoxicity (respectively, 0.24 and 0.31 patients).

\section{Discussion}

Our "two-step" analysis showed that the reporting patterns for life-threatening hepatic AEs were quite different among the drugs of interest, with higher reporting of autoimmune hepatitis and DILI with UPA, whereas similar physiochemical features were shared with mifepristone (Table 2), indicating that investigation of underlying pharmacological mechanisms is required, especially exploring the immune-mediated hypothesis.

Notably, specific pharmacological properties of UPA may explain the non-negligible reporting of certain hepatic DMEs. In particular, a minor reactive, partially characterized metabolite was detected in human faeces, proposed to be a glutathione conjugate of mono-oxygenated UPA. This proposed structure is consistent with the oxidation of the 4,5 carbon atoms to a reactive epoxide, followed by deactivation through glutathione conjugation [25]. This reactive metabolite may covalently bind to a protein and form a hapten-protein adduct and thereby elicit an adaptive immune response in susceptible individuals, potentially leading to occurrence of autoimmune hepatitis and DILI. Furthermore, this phenomenon may be enhanced by high lipophilicity and inhibition of breast cancer resistance protein (BCRP) in liver cells as well as predicted bile salt export pump (BSEP) inhibition in silico by UPA. Finally, dose dependency may also play a 
Table 1 Summary of spontaneous reports retrieved from the FAERS database concerning ulipristal acetate and mifepristone

\begin{tabular}{|c|c|c|c|}
\hline FAERS parameters & Ulipristal acetate & Mifepristone & Leuprolide acetate \\
\hline Total reports & 578 & 6220 & 44,079 \\
\hline \multicolumn{4}{|l|}{ Age distribution, years } \\
\hline$<18$ & $20(3.4)$ & $116(1.9)$ & $1609(3.7)$ \\
\hline $18-64$ & $364(63.0)$ & $4686(75.3)$ & $12,414(28.2)$ \\
\hline $65-85$ & $0(0.0)$ & $123(2.0)$ & $10,021(22.7)$ \\
\hline$>85$ & $0(0.0)$ & $3(0.1)$ & $1713(3.9)$ \\
\hline Not specified & $194(33.6)$ & $1292(20.7)$ & $18,322(41.5)$ \\
\hline Serious case & $532(92.0)$ & $3177(51.1)$ & $27,258(61.8)$ \\
\hline Proportion of deaths & $5(0.9)$ & $274(4.4)$ & $6860(15.6)$ \\
\hline \multirow[t]{11}{*}{ Most frequent AEs } & Unintended pregnancy & Haemorrhage & Hot flush \\
\hline & $159(27.5)$ & $1748(28.1)$ & $4203(9.5)$ \\
\hline & Abortion spontaneous & Abortion incomplete & Death \\
\hline & $107(18.5)$ & $1714(27.6)$ & $3997(9.1)$ \\
\hline & Vaginal haemorrhage & Pregnancy & Headache \\
\hline & $64(11.1)$ & $766(12.3)$ & $2185(5.0)$ \\
\hline & Drug ineffective & Anaemia & Fatigue \\
\hline & $44(7.6)$ & $586(9.4)$ & $2074(4.7)$ \\
\hline & Pregnancy after post- & Nausea & Pain \\
\hline & coital contraception & $493(7.9)$ & $1757(4.0)$ \\
\hline & $43(7.4)$ & & \\
\hline Hepatobiliary disorders & $17(2.9)$ & $48(0.8)$ & $722(1.6)$ \\
\hline Mean age & $36.6 \pm 9.0$ & $40.5 \pm 16.5$ & $63.0 \pm 19.1$ \\
\hline Sex & $16 \mathrm{~F} ; 1 \mathrm{NA}$ & $25 \mathrm{~F} ; 22 \mathrm{NA} ; 1 \mathrm{M}$ & $218 \mathrm{~F} ; 33 \mathrm{NA} ; 471 \mathrm{M}$ \\
\hline Serious & $17(100.0)$ & $45(93.8)$ & $677(93.8)$ \\
\hline Proportion of deaths & $0(0.0)$ & $3(6.3)$ & $129(17.9)$ \\
\hline \multicolumn{4}{|l|}{ Reporter country } \\
\hline Germany & 6 & - & 9 \\
\hline Italy & 3 & - & 13 \\
\hline Spain & 3 & - & 10 \\
\hline France & 2 & 2 & 40 \\
\hline UK & 1 & - & 7 \\
\hline Portugal & 1 & - & 2 \\
\hline Hungary & 1 & - & 3 \\
\hline USA & - & 32 & 119 \\
\hline Canada & - & 1 & 45 \\
\hline Saudi Arabia & - & 1 & \\
\hline Japan & - & - & 115 \\
\hline Other & - & - & 60 \\
\hline Not specified & - & 12 & 292 \\
\hline \multicolumn{4}{|l|}{ Reason for use } \\
\hline Uterine leiomyoma & 11 & - & 17 \\
\hline Menometrorrhagia & 6 & - & 5 \\
\hline Dysmenorrhoea & 5 & - & 1 \\
\hline Post-coital contraception & 3 & - & - \\
\hline Cushing's syndrome & - & 35 & - \\
\hline Abortion induced & - & 8 & - \\
\hline Placenta accreta & - & 1 & - \\
\hline Endometriosis & - & - & 67 \\
\hline Prostate/breast cancer & - & - & 404 \\
\hline NA & - & 4 & 228 \\
\hline
\end{tabular}


Table 1 (continued)

\begin{tabular}{|c|c|c|c|}
\hline FAERS parameters & Ulipristal acetate & Mifepristone & Leuprolide acetate \\
\hline \multicolumn{4}{|c|}{ Hepatic DMEs at PT level (ROR; 95\% CI) } \\
\hline Autoimmune hepatitis & $5(40.6 ; 16.8-97.9)$ & $1(\mathrm{NC})$ & $3(0.32 ; 0.10-0.98)$ \\
\hline Drug-induced liver injury & $5(14.2 ; 5.9-34.3)$ & $3(0.78 ; 0.25-2.43)$ & $7(0.26 ; 0.12-0.54)$ \\
\hline Acute hepatic failure & $5(22.5 ; 9.3-54.2)$ & - & $5(0.29 ; 0.15-0.70)$ \\
\hline Hepatic failure & $2(\mathrm{NC})$ & $8(0.91 ; 0.45-1.81)$ & $32(0.51 ; 0.36-0.72)$ \\
\hline Hepatic necrosis & - & - & $3(0.23 ; 0.07-0.70)$ \\
\hline Hepatitis fulminant & - & - & $10(1.74 ; 0.94-3.24)$ \\
\hline Concomitant agents (category) ${ }^{\mathrm{a}}$ & & & $\mathrm{b}$ \\
\hline None & 6 & & 15 \\
\hline Pantoprazole (C) & 5 & & - \\
\hline Metamizole (E) & 4 & & - \\
\hline Doxycycline (C) & 3 & & - \\
\hline Decapeptyl (E) & 2 & & - \\
\hline Desogestrel (A) & 2 & & - \\
\hline Lansoprazole (C) & 1 & & 1 \\
\hline Atorvastatin (A) & 1 & & - \\
\hline Metoclopramide (E) & 1 & & - \\
\hline Indapamide (E) & 1 & & - \\
\hline Ethinylestradiol/Levonorgestrel (A) & 1 & & - \\
\hline Verapamil (C) & - & & 1 \\
\hline Triamterene (D) & - & & 1 \\
\hline Valsartan (D) & - & & 1 \\
\hline Tramadol (E) & - & & 1 \\
\hline
\end{tabular}

Data are presented as mean \pm standard deviation or $\mathrm{N}(\%)$ unless otherwise indicated

$A E$ adverse event, $C I$ confidence interval, $D M E$ designated medical event, $F$ female, FAERS US FDA Adverse Event Reporting System, $M$ male, $N A$ not available, $N C$ not calculated, $P T$ preferred term, $R O R$ reporting odds ratio

a Based on classification reported in Björnsson et al. [11]. Number of convincing reports in the published literature: category A, $\geq 50$; B, 12-49; C, 4-11; D, 1-3; E, none

${ }^{\mathrm{b}}$ Extracted from the 17 reports in which leuprolide acetate was used in the management of uterine leiomyoma

role in the occurrence of DILI [26]. Although UPA is used at low dosages for the management of uterine fibroids (onesixth of the scheduled dosage for emergency contraception), the long-term course of treatment (up to 12 weeks) coupled with the extended half-lives of UPA and its main active metabolite PGL4002 (> 24 h) may lead to dose-dependent accumulation causing hepatotoxicity [20,27]. Consequently, we fully endorse the PRAC recommendations that encourage strict monitoring of liver function up to 4 weeks after stopping treatment with UPA.

Although prediction tools showed no risk of hepatotoxicity, except for cholestasis potentially due to mifepristone, both UPA and mifepristone exhibited dose- and $C_{\max }{ }^{-}$ based DILI scores ranging from 4.4 to 5.75 , resulting in less DILI concern/weak evidence (similar to amiodarone, entacapone, moxifloxacin) compared with drugs associated with severe hepatotoxicity risk (i.e., tolcapone, which was withdrawn from the market). These findings are in line with real-world data showing sporadic cases of severe liver injury associated with UPA compared with a postmarketing exposure estimated at $>765,000$ patients [5]. Furthermore, cases of cholestatic DILI caused by mifepristone were recently reported [28, 29], supporting predicted data from in silico models.

Conversely, leuprolide acetate exhibits contrasting physiochemical and pharmacokinetic properties (poor lipophilicity, parenteral administration, lack of hepatic metabolism), with low dose- and $\mathrm{C}_{\max }$-based DILI scores $(<0.5)$ resulting in no DILI concern/no evidence of hepatotoxicity. These findings are confirmed by literature data, where leuprolide acetate is classified as an unlikely cause of clinically apparent liver injury, given that only mild serum enzyme elevations in 3-5\% of patients were reported [30]. Furthermore, most cases of elevated transaminase levels were not associated with a direct impact of the agent on liver function but were caused by non-alcoholic fatty liver arising from metabolic changes due to an androgen-deprivation state induced by leuprolide acetate. 
Table 2 Summary of physiochemical and pharmacokinetic (PK) features of ulipristal acetate and mifepristone potentially involved in druginduced liver injury [13, 16-18, 20-25]

\begin{tabular}{|c|c|c|c|c|c|c|}
\hline Physiochemical and PK features & Ulipristal acetate & $\begin{array}{c}\text { Fulfilled } \\
\text { criteria }\end{array}$ & Mifepristone & $\begin{array}{c}\text { Fulfilled } \\
\text { criteria }\end{array}$ & $\begin{array}{c}\text { Leuprolide } \\
\text { acetate }\end{array}$ & $\begin{array}{c}\text { Fulfilled } \\
\text { criteria }\end{array}$ \\
\hline \multicolumn{7}{|l|}{ Physiochemical factors } \\
\hline Molecular weight (> $600 \mathrm{Da})$ & 475.6 & X & 429.6 & X & 1209.4 & $\sqrt{ }$ \\
\hline Scheduled daily dose ( $\geq 50-100 \mathrm{mg} /$ day $)$ & 5 & $\mathrm{X}$ & 200 & $\checkmark$ & $\begin{array}{c}\text { not available } \\
\text { per os }\end{array}$ & $\mathrm{X}$ \\
\hline Lipophilicity $(\log \mathrm{P} \geq 3)$ & 4.45 & $\checkmark$ & 5.33 & $\checkmark$ & 1.04 & $x$ \\
\hline Topological polar surface area $(<75 \AA 2)$ & 63.7 & $\checkmark$ & 40.5 & $\checkmark$ & 429.04 & $x$ \\
\hline $\mathrm{C}_{\text {plasma }} / \mathrm{BSEP} \mathrm{IC}_{50} \geq 0.1$ & No data & (?) & No data & (?) & No data & ? \\
\hline \multicolumn{7}{|l|}{ Oxidative stress } \\
\hline Reactive metabolites formation & $\begin{array}{l}\text { A reactive metabolite was } \\
\text { retrieved in faeces* }\end{array}$ & $\checkmark$ & No & $x$ & No & $x$ \\
\hline "Rule-of-two" & Negative (daily dose $<50 \mathrm{mg}$ ) & $x$ & Positive & $\checkmark$ & Negative & $x$ \\
\hline \multicolumn{7}{|l|}{ Mitochondrial liability } \\
\hline Mitochondrial dysfunction & No data & ? & No data & (?) & No data & ? \\
\hline \multicolumn{7}{|l|}{ Metabolism } \\
\hline Hepatic metabolism & $\begin{array}{l}\text { CYP 3A4+++ } \\
\text { CYP 1A2 }+ \\
\text { CYP 2D6+ }\end{array}$ & $\checkmark$ & CYP 3A4+++ & $\checkmark$ & No & $x$ \\
\hline \multicolumn{7}{|l|}{ Hepatic transporters } \\
\hline BSEP inhibition & $\begin{array}{c}\text { No (in vitro) } \\
\text { Positive [1.00] } \\
\text { (predicted in silico) }\end{array}$ & $x$ & $\begin{array}{c}\text { Yes (in vitro) } \\
\text { Positive [1.00] } \\
\text { (predicted in silico) }\end{array}$ & $\gamma$ & $\begin{array}{r}-(\text { in vitro }) \\
\text { Pos }[1.00] \\
(\text { in silico })\end{array}$ & \\
\hline MRP 2 transport & $\begin{array}{c}\text { No data (in vitro) } \\
\text { Positive [0.60] } \\
\text { (predicted in silico) }\end{array}$ & ? & $\begin{array}{c}\text { No data (in vitro) } \\
\text { Negative [0.40] } \\
\text { (predicted } \text { in silico) }\end{array}$ & $\begin{array}{l}\text { ? } \\
\times\end{array}$ & $\begin{array}{c}-(\text { in vitro }) \\
\mathrm{Neg}[0.00] \\
(\text { in silico })\end{array}$ & $\begin{array}{l}(?) \\
\times\end{array}$ \\
\hline MRP 3 inhibition & $\begin{array}{l}\text { No data (in vitro) } \\
\text { Positive [1.00] } \\
\text { (predicted } \text { in silico) }\end{array}$ & $\begin{array}{l}P \\
\checkmark\end{array}$ & $\begin{array}{l}\text { No data (in vitro) } \\
\text { Positive [1.00] } \\
\text { (predicted } \text { in silico) }\end{array}$ & (?) & $\begin{array}{r}-(\text { in vitro) } \\
\text { Pos [1.00] } \\
\text { (in silico) }\end{array}$ & $\begin{array}{l}\text { P? } \\
\checkmark\end{array}$ \\
\hline MRP 4 inhibition & $\begin{array}{l}\text { No data (in vitro) } \\
\text { Positive [1.00] } \\
\text { (predicted } \text { in silico) }\end{array}$ & $?$ & $\begin{array}{c}\text { No data (in vitro) } \\
\text { Positive [1.00] } \\
\text { (predicted in silico) }\end{array}$ & $\begin{array}{l}? \\
V\end{array}$ & $\begin{array}{r}-(\text { in vitro }) \\
\text { Pos }[1.00] \\
\text { (in silico) }\end{array}$ & $\begin{array}{l}? \\
V\end{array}$ \\
\hline P-glycoprotein inhibition & $\begin{array}{c}\text { Yes (in vitro) } \\
\text { Positive [0.66] } \\
\text { (predicted in silico) }\end{array}$ & $\begin{array}{l}\checkmark \\
\checkmark\end{array}$ & $\begin{array}{c}\text { Yes (in vitro) } \\
\text { Positive [0.91] } \\
\text { (predicted } \text { in silico) }\end{array}$ & $\checkmark$ & $\begin{array}{r}-(\text { in vitro }) \\
\text { Pos [0.97] } \\
\text { (in silico) }\end{array}$ & ? \\
\hline BCRP inhibition & $\begin{array}{c}\text { Yes at high dose (in vitro) } \\
\text { Negative }[0.21] \\
\text { (predicted in silico) }\end{array}$ & $\begin{array}{l} \\
x\end{array}$ & $\begin{array}{c}\text { Yes (in vitro) } \\
\text { Positive [0.69] } \\
\text { (predicted } \text { in silico) }\end{array}$ & $\gamma$ & $\begin{array}{l}\text { - (in vitro) } \\
\text { Neg }[0.13] \\
\text { (in silico) }\end{array}$ & $\begin{array}{l}(?) \\
\times\end{array}$ \\
\hline OATP1B1 inhibition & $\begin{array}{c}\text { No (in vitro) } \\
\text { Positive [1.00] } \\
\text { (predicted } \text { in silico) }\end{array}$ & $\begin{array}{l}x \\
V\end{array}$ & $\begin{array}{c}\text { Yes (in vitro) } \\
\text { Positive [1.00] } \\
\text { (predicted } \text { in silico) }\end{array}$ & 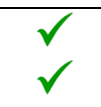 & $\begin{array}{r}-(\text { in vitro }) \\
\text { Pos }[1.00] \\
\text { (in silico) }\end{array}$ & $\begin{array}{l}(?) \\
\checkmark\end{array}$ \\
\hline OATP1B3 inhibition & $\begin{array}{c}\text { No (in vitro) } \\
\text { Positive [1.00] } \\
\text { (predicted } \text { in silico) }\end{array}$ & $\begin{array}{l}x \\
y\end{array}$ & $\begin{array}{c}\text { Yes (in vitro) } \\
\text { Positive [1.00] } \\
\text { (predicted } \text { in silico) }\end{array}$ & $\begin{array}{l}\checkmark \\
\checkmark\end{array}$ & $\begin{array}{r}-(\text { in vitro) } \\
\text { Pos [1.00] } \\
\text { (in silico) }\end{array}$ & $\begin{array}{l}\text { ? } \\
\checkmark\end{array}$ \\
\hline \multicolumn{7}{|l|}{ DILI risk score and prediction } \\
\hline ADVERPred & Negative & $\mathrm{X}$ & Negative & $x$ & Negative & $x$ \\
\hline \multirow{4}{*}{$\begin{array}{l}\text { Vienna LiverTox Workspace } \\
\text { Drug-induced liver injury } \\
\text { Hyperbilirubinemia } \\
\text { Cholestasis }\end{array}$} & \multirow{4}{*}{$\begin{array}{l}0.30 \\
0.27 \\
0.03\end{array}$} & & \multirow{4}{*}{$\begin{array}{l}0.12 \\
0.02 \\
1.00\end{array}$} & & \multirow{4}{*}{$\begin{array}{l}0.59 \\
0.24 \\
0.75\end{array}$} & \\
\hline & & $x$ & & $x$ & & $\sqrt{ }$ \\
\hline & & $x$ & & $x$ & & $x$ \\
\hline & & $x$ & & $\checkmark$ & & $\checkmark$ \\
\hline Dose-based DILI score**** & 4.82 & $\begin{array}{c}\text { less- } \\
\text { DILI- } \\
\text { concern }\end{array}$ & 4.43 & $\begin{array}{c}\text { less- } \\
\text { DILI- } \\
\text { concern }\end{array}$ & 0.24 & $\begin{array}{c}\text { no- } \\
\text { DILI- } \\
\text { concern }\end{array}$ \\
\hline $\mathrm{C}_{\max }$-based DILI score*** & 5.75 & $\begin{array}{c}\text { less- } \\
\text { DILI- } \\
\text { concern }\end{array}$ & 4.40 & $\begin{array}{c}\text { less- } \\
\text { DILI- } \\
\text { concern }\end{array}$ & 0.31 & $\begin{array}{c}\text { no- } \\
\text { DILI- } \\
\text { concern }\end{array}$ \\
\hline
\end{tabular}

$B C R P$ breast cancer resistance protein, $B S E P$ bile salt export pump, $C_{\max }$ peak concentration, $C$ plasma serum concentration, $C Y P$ cytochrome $\mathrm{P} 450, D I L I$ drug-induced liver injury, $I C_{50}$ half-maximal inhibition, $M R P$ multidrug resistance-associated protein, $N A$ not available, Neg negative, $O A T P 1 B$ organic anion-transporting polypeptide, $P o s$ positive +++ extensive metabolism by CYP450, ++ moderate metabolism by CYP450, + low metabolism by CYP450 
Table 2 (continued)

${ }^{a}$ Glutathione conjugate of mono-oxygenated ulipristal acetate. This proposed structure is consistent with the oxidation of the 4,5 carbon atoms to a reactive epoxide, followed by deactivation through glutathione conjugation

${ }^{\mathrm{b}}$ A score close to 1 indicates a high probability of causing DILI, hyperbilirubinemia, or cholestasis. A score close to 0 indicates a high probability of not causing DILI, hyperbilirubinemia, or cholestasis

${ }^{\mathrm{c}}$ Drugs receiving a score $>7$, between 3 and 7, and $<3$ show, respectively, most DILI concern/solid evidence, less DILI concern/weak evidence, and no DILI concern/no evidence of hepatotoxicity

From a clinical perspective, the EMA's current suspension of marketing authorization for UPA may pose major issues in daily practice, as the efficacy of UPA in reducing fibroid-associated bleeding, duration of surgery, frequency of blood transfusions, and fibroid size when used in the preoperative treatment of uterine fibroids is recognized [31-35]. Additionally, current evidence suggests that prolonged use of UPA may be a good alternative to other more invasive treatment modalities, particularly for clinical scenarios such as bridging the gap until menopause or in the younger patient to minimize symptoms until pregnancy is desired [32]. In this scenario, leuprolide acetate should be considered a potential alternative, given its proven efficacy in reducing fibroid size, intraoperative blood loss, and the frequency of blood transfusion [32-35]; however, clinical trials have reported a significantly higher occurrence of hot flushes compared with UPA, and our findings confirm this [33]. Although no signals of DILI emerged for leuprolide acetate in our pharmacovigilance analysis, a non-negligible number of serious AEs was reported, mostly in different clinical scenarios with respect to UPA (namely older patients affected by advanced prostatic or breast cancer).

As a whole, the hepatotoxic liability of UPA (and its potential definite withdrawal) must be balanced against two main clinical aspects: (1) a potentially significant increase in the number of minor and major surgeries for uterine fibroids, as already seen after the first suspension in 2018 [36], with possible increases in postoperative complications; and (2) the risk/benefit profile of medical alternatives (leuprolide acetate) in the light of real-life findings.

We acknowledge the limitations of this study, related to both pharmacovigilance analyses, including FAERS data (e.g., quality of reports, potential existence of remaining duplicates, reporting biases, lack of exposure data, inability to establish firm causality between drug exposure and occurrence of AEs, and limited verification of events through clinical features) and pharmacokinetic/pharmacodynamic assessment. We selected three agents with different markets, indications, treatment durations, and mechanisms of action, which meant comparison was difficult, particularly given the lack of a clear DILI effect with these drugs. Our study was intended to be a proof of concept, and the design or validation of a predictive model/algorithm for DILI assessment was out of our scope. According to publicly available information, Novartis is developing an algorithm called the 'DILI cluster score' using pharmacokinetic and physiochemical properties to predict the risk for orally administered drugs [37].

\section{Conclusion}

The over-reporting of severe life-threatening hepatic reactions, including autoimmune hepatitis, associated with UPA in post-marketing surveillance may be partially explained by its physiochemical (high lipophilicity) and pharmacokinetic (hepatic metabolism, long half-life, inhibition of liver transporters, reactive metabolite formation) features. These findings indicate the need for further investigations to clarify the mechanistic basis of DILI, which remains unsatisfactory, and underline the unpredictable nature of liver damage in clinical practice. We call on clinicians to raise awareness about the rare occurrence of DILI with UPA even in patients without apparent risk factors. This "bedside-to-bench" pharmacological approach may aid regulators in exploring the underlying mechanisms subtending DILI recognised in postmarketing surveillance, thus supporting issued regulatory warnings.

Acknowledgements Open access funding provided by Alma Mater Studiorum - Universit $\tilde{A}$ di Bologna within the CRUI-CARE Agreement.

\section{Declarations}

Funding ER, EP \& FDP at the University of Bologna are supported by institutional research funds (Ricerca Fondamentale Orientata). The study was not funded in whole or in part by any research grant or funding body.

Conflicts of interest MG, EP, FDP, and ER have no conflicts of interest that are directly relevant to the content of this article.

Ethics approval Not applicable.

Consent to participate Not applicable.

Consent for publication Not applicable.

Availability of Data and Material Data supporting the findings of this study were derived from the following resource, which is available in the public domain: https://fis.fda.gov/sense/app/d10be6bb-494e-4cd282e4-0135608ddc13/sheet/7a47a261-d58b-4203-a8aa-6d3021737452/ state/analysis.

Code availability Not applicable. 
Author Contributions ER made substantial contributions to the conception and design of the study. MG made substantial contributions to the acquisition and analysis of data. MG, ER, EP, and FDP made substantial contributions to interpretation of the data. MG was involved in drafting the manuscript. ER, EP, and FDP made substantial contributions to critically revising the manuscript for important intellectual content. All authors approved the final version of the manuscript.

Open Access This article is licensed under a Creative Commons Attribution-NonCommercial 4.0 International License, which permits any non-commercial use, sharing, adaptation, distribution and reproduction in any medium or format, as long as you give appropriate credit to the original author(s) and the source, provide a link to the Creative Commons licence, and indicate if changes were made. The images or other third party material in this article are included in the article's Creative Commons licence, unless indicated otherwise in a credit line to the material. If material is not included in the article's Creative Commons licence and your intended use is not permitted by statutory regulation or exceeds the permitted use, you will need to obtain permission directly from the copyright holder. To view a copy of this licence, visit http://creativecommons.org/licenses/by-nc/4.0/.

\section{References}

1. Rabe T, Saenger N, Ebert AD, Roemer T, Tinneberg HR, De Wilde RL, Wallwiener M. Selective progesterone receptor modulators for the medical treatment of uterine fibroids with a focus on ulipristal acetate. Biomed Res Int. 2018;24(2018):1374821.

2. Ulipristal acetate (Esmya): restrictions on use. Drug Ther Bull. 2018;56(11):127. https://doi.org/10.1136/dtb.2018.11.000033.

3. European Medicines Agency. Esmya Article-20 procedure - Scientific conclusions. https://www.ema.europa.eu/en/documents/refer ral/esmya-article-20-procedure-scientific-conclusions_en.pdf. Accessed 12 Apr 2020.

4. European Medicines Agency. Esmya: new measures to minimise risk of rare but serious liver injury. https://www.ema.europa.eu/ en/documents/referral/esmya-article-20-procedure-esmya-newmeasures-minimise-risk-rare-serious-liver-injury_en-0.pdf. Accessed 12 Apr 2020.

5. Donnez J. Liver injury and ulipristal acetate: an overstated tragedy? Fertil Steril. 2018;110(4):593-5. https://doi.org/10.1016/j. fertnstert.2018.06.044.

6. Donnez J, Arriagada P, Marciniak M, Larrey D. Liver safety parameters of ulipristal acetate for the treatment of uterine fibroids: a comprehensive review of the clinical development program. Expert Opin Drug Saf. 2018;17(12):1225-32. https:// doi.org/10.1080/14740338.2018.1550070.

7. Del Forno S, Degli Esposti E, Salucci P, Leonardi D, Iodice R, Arena A, Raimondo D, Paradisi R, Seracchioli R. Liver function, tolerability and satisfaction during treatment with ulipristal acetate in women with fibroids: a single center experience. Gynecol Endocrinol. 2019. https://doi.org/10.1080/09513590.2019.16806 26 (Epub ahead of print).

8. European Medicines Agency. Suspension of ulipristal acetate for uterine fibroids during ongoing EMA review of liver injury risk. https://www.ema.europa.eu/en/documents/referral/ulipristal -acetate-5mg-medicinal-products-article-31-referral-review-start ed_en.pdf. Accessed 11 Apr 2020.

9. European Medicines Agency. Designated Medical Event (DME) list. 2016. https://www.ema.europa.eu/en/human-regulatory/postauthorisation/pharmacovigilance/signal-management\#designated -medical-events-section. Accessed 8 Apr 2020.
10. Antonazzo IC, Poluzzi E, Forcesi E, Riise T, Bjornevik K, Baldin E, Muratori L, De Ponti F, Raschi E. Liver injury with drugs used for multiple sclerosis: a contemporary analysis of the FDA Adverse Event Reporting System. Mult Scler. 2019;25(12):163340. https://doi.org/10.1177/1352458518799598.

11. Björnsson ES, Hoofnagle JH. Categorization of drugs implicated in causing liver injury: critical assessment based on published case reports. Hepatology. 2016;63(2):590-603.

12. DeHart RM, Morehead MS. Mifepristone. Ann Pharmacother. 2001;35(6):707-19.

13. Periti P, Mazzei T, Mini E. Clinical pharmacokinetics of depot leuprorelin. Clin Pharmacokinet. 2002;41(7):485-504.

14. Raschi E, De Ponti F. Strategies for early prediction and timely recognition of drug-induced liver injury: the case of cyclin-dependent kinase 4/6 inhibitors. Front Pharmacol. 2019;24(10):1235. https ://doi.org/10.3389/fphar.2019.01235.

15. European Association for the Study of the Liver. EASL Clinical Practice Guidelines: drug-induced liver injury. J Hepatol. 2019;70:1222-61. https://doi.org/10.1016/j.jhep.2019.02.014.

16. Ivanov S.M., Lagunin A.A., Rudik A.V., Filimonov D.A., Poroikov V.V. ADVERPred-web service for prediction of adverse effects of drugs. Journal of Chemical Information and Modeling, 2018; 58(1): 8-11 (https://doi.org/10.1021/acs.jcim.7b00568). http://www.way2drug.com/adverpred/. Accessed 11 Apr 2020.

17. Montanari F, Knasmüller B, Kohlbacher S, Hillisch C, Baierová C, Grandits M, Ecker GF. Vienna LiverTox workspace-a set of machine learning models for prediction of interactions profiles of small molecules with transporters relevant for regulatory agencies. Front Chem. 2020;7:899. https://doi.org/10.3389/fchem .2019.00899. https://livertox.univie.ac.at/. Accessed 11 Apr 2020.

18. Chen M, Borlak J, Tong W. A Model to predict severity of druginduced liver injury in humans. Hepatology. 2016;64(3):931-40. https://doi.org/10.1002/hep.28678.

19. Mishra P, Chen M. Direct-acting antivirals for chronic hepatitis C: can drug properties signal potential for liver injury? Gastroenterology. 2017;152(6):1270-4. https://doi.org/10.1053/j.gastr o.2017.03.012.

20. Ferrero S, Vellone VG, Barra F. Pharmacokinetic drug evaluation of ulipristal acetate for the treatment of uterine fibroids. Expert Opin Drug Metab Toxicol. 2018;14(1):107-16. https:// doi.org/10.1080/17425255.2018.1417389.

21. Pohl O, Zobrist RH, Gotteland JP. The clinical pharmacology and pharmacokinetics of ulipristal acetate for the treatment of uterine fibroids. Reprod Sci. 2015;22(4):476-83. https://doi. org/10.1177/1933719114549850.

22. Sarkar NN. Mifepristone: bioavailability, pharmacokinetics and use-effectiveness. Eur J Obstet Gynecol Reprod Biol. 2002;101(2):113-20.

23. Heikinheimo O. Clinical pharmacokinetics of mifepristone. Clin Pharmacokinet. 1997;33(1):7-17.

24. https://www.drugbank.ca/. Accessed 11 Apri 2020.

25. European Medicines Agency. Assessment report on Esyma, May 17, 2018. https://www.ema.europa.eu/en/documents/refer ral/esmya-article-20-procedure-prac-assessment-report_en.pdf. Accessed 12 April 2020.

26. Roth RA, Ganey PE. Intrinsic versus idiosyncratic drug-induced hepatotoxicity-two villains or one? J Pharmacol Exp Ther. 2010;332(3):692-7.

27. Meunier L, Meszaros M, Pageaux GP, Delay JM, Herrero A, Pinzani V, Dominique HB. Acute liver failure requiring transplantation caused by ulipristal acetate. Clin Res Hepatol Gastroenterol. 2020. https://doi.org/10.1016/j.clinre.2020.02.008 (Epub ahead of print).

28. Shah I, Putnam T, Daugherty E, Vyas N, Chuang KY. Mifepristone: an uncommon cause of drug-induced liver injury. Gastroenterol Res. 2019;12(3):181-4. https://doi.org/10.14740/gr1188. 
29. Funke K, Rockey DC. Cholestatic drug-induced liver injury caused by mifepristone. Hepatology. 2019;69(6):2704-6. https:// doi.org/10.1002/hep.30465.

30. LiverTox: Clinical and Research Information on Drug-Induced Liver Injury [Internet]. Leuprolide. Bethesda (MD): National Institute of Diabetes and Digestive and Kidney Diseases; 2012-. 2018.

31. Pérez-López FR, Ornat L, Ceausu I, Depypere H, Erel CT, Lambrinoudaki I, Schenck-Gustafsson K, Simoncini T, Tremollieres F, Rees M, EMAS. EMAS position statement: management of uterine fibroids. Maturitas. 2014;79(1):106-16. https://doi. org/10.1016/j.maturitas.2014.06.002.

32. Laberge PY, Murji A, Vilos GA, Allaire C, Leyland N, Singh SS. Guideline No. 389-medical management of symptomatic uterine leiomyomas - an addendum. J Obstet Gynaecol Can. 2019;41(10):1521-4. https://doi.org/10.1016/j.jogc.2019.01.010.

33. Lethaby A, Puscasiu L, Vollenhoven B. Preoperative medical therapy before surgery for uterine fibroids. Cochrane Database Syst Rev. 2017;11:CD000547. https://doi.org/10.1002/14651858. cd000547.pub2.
34. de Milliano I, Twisk M, Ket JC, Huirne JA, Hehenkamp WJ. Pre-treatment with GnRHa or ulipristal acetate prior to laparoscopic and laparotomic myomectomy: A systematic review and meta-analysis. PLoS One. 2017;12(10):e0186158. https://doi. org/10.1371/journal.pone.0186158 (eCollection 2017).

35. Ghonim M, Magdy R, Sabbour M, Ghonim M, Nabhan A. A systematic review and meta-analysis of ulipristal acetate for symptomatic uterine fibroids. Int J Gynaecol Obstet. 2019;146(2):141-8. https://doi.org/10.1002/ijgo.12868.

36. Indraccolo U, Conzadori S, Greco P. Which is the destiny of ulipristal acetate for uterine fibroids? A commentary on the Italian medicines agency (AIFA) pronouncements. Recent Prog Med. 2019;110:98-9.

37. Kullak-Ublick GA, Andrade RJ, Merz M, End P, Benesic A, Gerbes AL, Aithal GP. Drug-induced liver injury: recent advances in diagnosis and risk assessment. Gut. 2017;66(6):1154-64. 